\title{
Seudoobstrucción intestinal crónica, hiperplasia nodular linfoide intestinal y endometriosis intestinal
}

\author{
A. BLANCO BARRIOS, F. ZANCADA DÍAZ DE ENTRE-SOTOS, A. RODRÍGUEZ \\ PÉREZ
}

Servicio de Medicina Interna. Hospital Virgen del Puerto. Plasencia. Cáceres.

${ }^{\prime}$ Departamento de Gastroenterología. Hospital Universitario. Salamanca

\begin{abstract}
PSEUDO-OBSTRUCTION CHRONIC DISEASE, LYMPHOID HYPERPLASIA OF THE GASTROINTESTINAL TRACT AND INTESTINAL ENDOMETRIOSIS
\end{abstract}

\begin{abstract}
RESUMEN
La presencia de hiperplasia nodular linfoide intestinal asociada a focos de endometriosis con comportamiento clínico de seudoobstrucción intestinal crónica y síndrome de malabsorción es una entidad infrecuente. Describimos el caso de una paciente de 32 años con este síndrome de año y medio de evolución clínica. El diagnóstico etiológico se realizó mediante laparotomía. Los últimos $30 \mathrm{~cm}$ del íleon presentaban signos inflamatorios con engrosamiento de la pared intestinal y se practicó resección de la zona afectada y anastomosis latero-lateral. El diagnóstico anatomopatológico fue de hiperplasia linfoide folicular con úlceras y fisuras mucosas, pseudopólipos inflamatorios, enteritis crónica profunda y focos de endometriosis. La evolución clínica de la paciente fue favorable tras la cirugía.
\end{abstract}

PALABRAS CLAVE: Hiperplasia nodular linfoide. Endometriosis. Malabsorción. Seudoobstrucción intestinal crónica.

\begin{abstract}
Nodular lymphoid hyperplasia of the gastrointestinal tract associated to endometriosis is an uncommon cause of chronic pseudo-obstruction and malabsortion. The case of a 32-year-old woman who suffered from this syndrome for one a half years is described.

Diagnosis was achieved by laparotomy, wich disclosed swelling and inflammation of the $30 \mathrm{~cm}$ terminal yeyunal portion. Removal of the involved intestine and side-to-side anastomosis were performed.

The pathological findings were: follicular lymphoid hyperplasia with mucosal ulcers an fissures inflammatory pseudo-polyps, chronic deep enteritis and areas of endometriosis. A favourable outcome followed surgery.
\end{abstract}

KEY WORDS: Giant lymph node hyperplasia. Endometriosis. Malabsortion síndrome intestinal. Pseudo-obstruction chronic disease.

Blanco Barrios A, Zancada Díaz de Entre-Sotos F, Rodríguez Pérez A. Seudoobstrucción intestinal crónica, hiperplasia nodular linfoide intestinal y endometriosis intestinal. An Med Interna (Madrid) 2003; 20: 624-626.

\section{INTRODUCCIÓN}

La seudoobstrucción intestinal crónica (SIC) es una entidad poco frecuente en adultos; no se dispone de estudios epidemiológicos de la enfermedad (1) y no se han descrito casos en que se halle asociado a una hiperplasia nodular linfoide (HNL) intestinal en relación con focos de endometriosis. La HNL supone una rareza como causa de obstrucción o SIC en adultos. Se han descrito casos de focos de endometriosis intestinal que se manifiestan por alteraciones de la función intestinal o por cuadros de obstrucción o SIC (2), diarrea, estreñimiento o rectorragias catameniales. La endometriosis de la pared intestinal constituye el 33\% de todas ellas, y se han descrito como localizaciones más frecuentes la uterina y la ovárica. Existen aspectos desconocidos sobre la histogénesis de la endometriosis; ésta es diferente a la de la adenomiosis (o tejido endometrial en el espesor del miometrio) y se han postulado diferentes teorías (teoría metaplásica, implantativa, propagación linfática, propagación hemática). Sin embargo, ninguna de ellas es aceptada por todos los autores (3). La HNL del intestino se supone debida a una reacción del tejido linfático intestinal ante un estímulo inflamatorio específico continuo. Este estímulo específico, en nuestro caso, sería la presencia de focos de endometriosis intestinal. En la revisión de la bibliografía no hemos encontrado asociación entre HNL intestinal, focos de endometriosis y cuadros de obstrucción o SIC.

\section{CASO APORTADO}

Mujer de 32 años, sin antecedentes patológicos de interés, sin hábitos tóxicos, ni alergias medicamentosas. No refería historia de

Trabajo aceptado: 29 de abril de 2003

Correspondencia: A. Blanco Barrios. C/ Isidoro García Polo, 2, dúplex F 1. 10600 Plasencia, Cáceres. e-mail: blancobarrios@ terra.es. 
viajes recientes. La madre había sido diagnosticada recientemente de un linfoma no Hodgkin con déficit de IgA. Acudió a consulta en el Servicio de Digestivo en marzo de 1997 por episodios de periodicidad mensual, de 5-6 días de duración, desde aproximadamente un año antes, de dolor continuo epigástrico y periumbilical con exacerbaciones cólicas con ruidos hidroaéreos audibles por la paciente y sus familiares. Lo relacionó con el diagnóstico de la enfermedad de la madre. Mejoraba con la provocación del vómito, con pirazolonas y menos con anti-H2. No refería otras manifestaciones. Durante este periodo la paciente había perdido $5-6 \mathrm{~kg}$ de peso a pesar de mantener el apetito. En la exploración física presentaba hábito leptosómico, palidez cutánea, abdomen distendido, timpanizado a la percusión, con chapoteo en fosa ilíaca derecha, borborigmos generalizados a la auscultación y pequeñas adenopatías inguinales bilaterales. Aportaba pruebas realizadas fuera del servicio: radiografía de tórax y de abdomen, tránsito esófago-gástrico-duodenal y TAC abdominal donde se observaba dilatación de asas de intestino delgado y edema de pared intestinal. Una revisión ginecológica no había encontrado alteraciones. Ante la sospecha de obstrucción o SIC se solicitaron reactantes de fase aguda, metabolismo de hierro, proteinograma, inmunoglobulinas, hemograma, anticuerpos antigliadina, hormonas tiroideas, anticuerpos antitiroglobulina, estudio de autoinmunidad, coprocultivos, parasitología y examen de heces que fueron normales. La ecografía abdominal, gastroscopia y colonoscopia fueron normales. En el enema opaco se observaba dolicomegacolon y dilatación de asas de intestino delgado. Se realizó gastroscopia con biopsias de duodeno y colonoscopia sin alteraciones. Grasa en heces de 24 h 14 g $(n<7)$. La paciente optó por no realizarse otros estudios y se trató con antibióticos de amplio espectro. Evolución: En los tres meses siguientes la evolución fue desfavorable, los episodios de dolor se hicieron continuos, con miedo a comer por intensificación del dolor y perdió $15 \mathrm{~kg}$ de peso. Se solicitaron nuevos exámenes: 4.500 leucocitos (N 57,2\%, L 29,3\%, Mo $11,2 \%$ ), Hb 8,5 g/dl, Hto $27 \%$, plaquetas 376000 , constantes corpusculares normales. SMA con metabolismo del hierro (sideremia $43 \mathrm{UG} / \mathrm{dl}$, ferritina $329 \mathrm{ng} / \mathrm{ml}$, transferrina $180 \mathrm{mg} / \mathrm{dl}$, CFTH 228,6 UG/dl, 18,8\%), vitamina $B_{12} 246 \mathrm{pg} / \mathrm{ml}$, ácido fólico $3,80 \mathrm{ng} / \mathrm{ml}$, ácido úrico $1,9 \mathrm{mg} / \mathrm{dl}$, fosfatasa alcalina $79 \mathrm{U} /$ litro, $\mathrm{LDH}$ $165 \mathrm{U} /$ litro, resto de parámetros normales. Proteínas totales 5,8 g/dl, albúmina $3 \mathrm{~g} / \mathrm{dl}$, a1 0,3 g/dl, a2 0,9 g/dl, b 0,7 g/dl, g-globulinas 0,8 g/dl. Estudio de coagulación: TP 68\%, TTPA 35" (N: 28-40), fibrinógeno $385 \mathrm{mg} / \mathrm{dl}$, VSG $15 \mathrm{~mm}$ en la primera hora. Ante la mala evolución del síndrome de SIC, con sospecha de un cuadro de SIC o de obstrucción intestinal crónica por un proceso linfomatoso, se decidió laparotomía. Desde 30-40 cm del ángulo de Treitz se observa dilatación de todas las asas de intestino delgado hasta la válvula ileocecal. Colon normal. Adenopatías mesentéricas. El último tramo ileal presentaba aspecto inflamatorio y se resecó. El diagnóstico anatomopatológico de urgencias de la pieza se informó de mucosa hemorrágica y polipoide, en " empedrado", acompañado de engrosamiento irregular de la pared por tejido fibroso. Se procedió a realizar anastomosis ileo-cólica latero-lateral. El análisis microscópico demostró HNL con úlceras y fisuras mucosas, pseudopólipos inflamatorios, enteritis quística profunda, zonas de endometriosis y linfadenitis reactiva en gánglio mesentérico. La evolución post-quirúrgica fue favorable. En el seguimiento a los 18 meses, la paciente se hallaba asintomática con recuperación ponderal completa.

\section{DISCUSIÓN}

La endometriosis es una entidad clínica que se define por la presencia de tejido similar al de la mucosa endometrial, tanto estructural como funcionalmente, en lugares distintos del que fisiológicamente ocupa en el endometrio. Existen dos formas diferentes de endometriosis, la adenomiosis en la cuál los focos de ectópicos de endometrio se localizan en el miometrio, y la endometriosis propiamente dicha, en la que se localizan fuera del útero. Se calcula que un $10 \%$ de las mujeres presentan alguna forma de endometriosis. Es rara en la raza negra y es más frecuente en mujeres de posición socioeconómica elevada, en mujeres que se casan en edades avanzadas y evitan la concepción, entre los 30-40 años y en mujeres nulíparas (a diferencia de la adenomiosis). Se acompaña de esterilidad en el 30-40\% de los casos en relación con la secreción de prostaglandinas, las cuales interfieren el mecanismo de la reproducción. El síntoma clínico más característico es la dispareunia intramenstrual, y otros síntomas que se relacionan con la localización de los focos de endometriosis; así, en caso de endometriosis intestinal pueden existir episodios de diarrea, estreñimiento o hemorragia catamenial. Los cuadros obstructivos o seudoobstructivos son más raros y más frecuentes en colon (2). Otras veces, cursa de forma asintomática. En el análisis microscópico de los focos de endometriosis se observan sus dos componentes glándulas y estroma. Pueden presentar diferentes aspectos funcionales, en ocasiones experimentan cambios cíclicos semejantes al endometrio normal, otras recuerdan a la capa basal del endometrio y no sufren los cambios secretorios y a veces incluso presentan claros signos de hiperplasia, o bien el epitelio que recubre las glándulas sufre alteraciones que hacen imposible su identificación. Puede sufrir transformación maligna en la localización ovárica en menos del 1\%. En ocasiones los cánceres pueden nacer de focos de endometriosis que más tarde son destruidos por el crecimiento del tumor o no diagnosticados por el patólogo, lo cual hace difícil saber la incidencia real. No hemos encontrado descritos casos de seudoobstrucción u obstrucción intestinal crónica en adultos por HNL asociada a endometriosis. La HNL intestinal a pesar de ser clínicamente benigna puede llegar a degenerar. En muchas ocasiones obliga a laparotomías diagnósticas con biopsias de espesor completo de la pared intestinal y a resecciones intestinales amplias para hacer el diagnóstico. Esta entidad se ha descrito asociada a inmunodeficiencias, sobre todo a la inmunodeficiencia común variable; hasta el $60 \%$ de los pacientes con inmunodeficiencia variable común o IDVC pueden presentar HNL intestinal. Estos pacientes presentan mayor frecuencia de enteritis crónica y un mayor riesgo de desarrollar cáncer (1). También se ha descrito la asociación de inmunodeficiencia variable común, HNL intestinal de células T y neumonitis intersticial linfoide nodular de células B e infecciones pulmonares recurrentes por bacterias piógenas que respondieron a tratamiento con corticoides. La HNL intestinal supone un incremento en el riesgo de linfoma de intestino delgado; en la asociación descrita en pacientes con IDVC e hiperplasia linfoide de intestino delgado complicada con linfoma maligno de yeyuno, los estudios inmunopatológicos demostraron que se trataba de un linfoma centroblástico polimorfo Ig M intracitoplasmáticas y cadenas ligeras $\lambda$. Otras asociaciones descritas de la HNL son, su mayor frecuente aparición en pacientes con disgammaglobulinemia adquirida, diarreas crónicas, sobrecrecimiento bacteriano e historia de infecciones recurrentes del tracto respiratorio superior, que respondieron a ciclos de corticoides y antibioterapia de amplio espectro (3 y 4 ), en amilodosis y en pacientes con infección crónica por VIH y con traslocación cromosómica $\mathrm{t}(2 ; 4)$ con diferentes puntos de ruptura, configurando el síndrome de Aarskog asociado a trombocitopenia autinmune (PTI), Anemia Hemolítica autoinmune (AHAI) Ig G e hiperplasia folicular linfoide gigante benigna (5). En nuestro caso, la HNL coincidía con 
focos de endometriosis, la paciente empeorara en los periodos peri y menstruales, si bien no disponemos de datos en la literatura. No se han descrito casos de SIC secundaria a HNL intestinal en relación con focos de endometriosis intestinal. La HNL sería secundaria al estímulo inflamatorio crónico

\section{Bibliografía}

1. Sleinsenger- Fortdram. Enfermedades Gastrointestinales 1995, Tomo I, $5^{a}$ edición.

2. Mundi Sánchez-Ramade, Carvia Ponsaille R, Pérez Ramón J.A, Carmona Soria I, Lavín Castejón I, Trapero Martínez A, Fernández Pérez R y Palacios Pérez A. Endometriosis: una causa infrecuente de obstrucción colónica. Gastroenterol Hepatol 1998; 21: 224-226

3. Brindici D, Grimaldi F, Fracella MR, Abrusci MR et al. Radiologic evaluation and prognosis of lymphoid nodular hyperplasia of the mesenteric específico que representarían los focos de endometriosis. Creemos conveniente no descartar esta posibilidad diagnóstica en mujeres en edad fértil que presenten clínica de obstrucción o SIC y orientamos a buscar focos de endometriosis entre la HLN intestinal en casos similares.

intestine. Radiol Med (Torino) 1993; 86 (5): 622-625.

4. Castaneda-Romero B, Díaz-Caldelas L, Galvan Guerra E, Sixtos S, Arista J, Uscanga L. Intestinal lymphoid nodular hyperplasia in a patient with acquired dysgammaglobulinemia, chronic diarrhea, and bacterial overgrowth syndrome. Rev Gastroenterol Mex 1993; 58 (3): 225-228.

5. F. Cabañete Reché; M.A. García López; M.A. Vázquez López; et al. An Esp Pediatr 1997; 46: 499-502. 